\title{
DO PATHOS TRÁGICO A POSSIBLIDADE DE AKRASIA EM PLATÃO
}

Glaucer Ferreira Silva ${ }^{1}$

Resumo: O presente estudo tem por objetivo analisar as disparidades existentes entre dois momentos fundamentais quanto à constituição da polis grega, a saber, o trágico e o ligado ao logos e à racionalidade, denominado período socrático/platônico. Primeiramente, lançaremos nosso olhar sobre o chamado período trágico da cultura helênica, buscando contemplar o homem enredado pelo pathos trágico e sua consequente idiossincrasia dionisíaca. Ainda no século $\mathrm{V}$ a.C. contemplaremos este que representa um dos principais pilares de sustentação da filosofia do período antropológico do pensamento grego: Platão. Contudo nos deteremos a alguns aspectos do socratismo tendo como ideia disparadora a possibilidade da akrasia. Deste modo entendemos que nos são apresentados dois modelos de homem: O ligado ao período trágico e o oferecido pela ética platônica guiado pelo logos. Utilizaremos como aporte teórico, a contribuição de helenistas como Jean-Pierre Vernant e Romilly, assim como o filósofo alemão Nietzsche. Quanto à contribuição platônica nos deteremos sobres os diálogos platônicos Laques, Protágoras e Górgias. Exatamente por sua importância quanto ao tema da akrasia nos diálogos da primeira fase platônica.

Palavras-chave: Platão; Akrasia; Pathos.

\section{FROM THE TRAGIC PATHOS THE POSSIBLITY OF ACRASIA IN PLATO}

\begin{abstract}
This study aims to analyze the disparities between two fundamental moments in the constitution of the Greek polis, namely, the tragic and the one linked to logos and rationality, called the Socratic / Platonic period. Firstly, we will look at the so-called tragic period of Hellenic culture, seeking to contemplate the man entangled by the tragic pathos and its consequent dionysian idiosyncrasy. Still in the 5th century BC we will contemplate this one which represents one of the main pillars of the philosophy of the anthropological period of Greek thought: Plato. However we will dwell on some aspects of Socratism with the triggering idea of the possibility of akrasia. Thus we understand that we are presented with two models of man: The one linked to the tragic period and the one offered by the Platonic ethics guided by the logos. We will use as a theoretical contribution the contribution of Hellenists such as JeanPierre Vernant and Romilly, as well as the German philosopher Nietzsche. As for the platonic contribution we will dwell on the platonic dialogues Laks, Protagoras and Gorgias. Precisely because of its importance on the theme of achrasia in the dialogues of the first Platonic phase.
\end{abstract}

Keywords: Plato; Akrasia; Pathos.

\footnotetext{
${ }^{1}$ Graduado no curso de Licenciatura Plena em Letras-Português pela Universidade Estadual do Piauí-UESPI (2014) e em Licenciatura Plena em Filosofia pela mesma instituição (2018). Atualmente é mestrando em Filosofia pela Universidade Federal do Piauí (UFPI), sendo bolsista CAPES. Tem como interesse de pesquisa temas da filosofia nietzschiana com ênfase em questões éticas e estéticas. E-mail: ferreiraglaucer@ gmail.com. Lattes: http://lattes.cnpq.br/8643616268133975.
} 


\section{INTRODUÇÃO}

O presente estudo tem como objetivo pensar o problema da akrasia em Platão e as consequentes transformações que a advento do pensamento socrático/platônico causaram na Grécia Clássica. Momento do nascimento da filosofia como a conhecemos: analítica; hipotética; refutativa. Procedimento imbrincado com ideias de verdade, realidade e forma.

$\mathrm{O}$ século $\mathrm{V}$ a.C. é marcado pela chamada era trágica da filosofia, mas também é neste mesmo século que assistimos ao desabrochar da filosofia socrático/platônica centrada no logos. Período em que se instaurava a chamada democracia ateniense aos auspícios do tirano Pisístrato $^{2}$. Como sabemos, o teatro grego era a ferramenta de educação do homem dessa época. Gostaríamos, nesta pesquisa de apontar, em um primeiro momento, para a importância do pathos trágico na educação helênica bem como suas consequências.

Platão não parecia ver a tragédia com bons olhos quanto à formação do homem grego. Em sua obra basilar A República assistimos a passagem da expulsão dos poetas de sua cidade ideal, contudo, em um de seus diálogos de juventude já podemos notar sua postura crítica quanto a essa questão.

Quanto à poesia trágica Platão nos diz que:

E essa poesia augusta e admirável, em pós de que se afana tanto? Qual te parece ser a sua finalidade e todo seu esforço? Terá o fito exclusivo de agradar os espectadores, ou poderá ir contra eles, na hipótese de apresentar algo agradável a todos e muito grato, porém pernicioso, que ela faça questão de silenciar, proclamando e cantando, pelo contrário, só o que for útil, porém desagradável, quer se alegre com isso os ouvintes, quer se aborreça? Dessas duas disposições qual imaginas que seja a da tragédia?" (GÓRGIAS 502 c).

É de modo paradoxal que Platão apresente na obra A República a ideia de que os apetites e as paixões também fazem parte do conhecimento. Neste diálogo em que Platão divide a alma em três partes e demostra que o homem dito acrático vive em constante desequilíbrio ou conflito entre as partes da alma; levando-o a desmesura ou hybris ${ }^{3}$.

O homem trágico é guiado pelas paixões, pelos sentimentos e pelo destino, seria um ácrata exatamente por se deixar levas pelas paixões, pelos desejos, em suma, por agir de modo passional e não racional. Não raro, o herói trágico é enredado numa trama que pode fazê-lo

\footnotetext{
${ }^{2}$ Pisístrato foi um dos maiores estimuladores para a criação e apresentação de tragédias, à sombra da Acrópole onde havia mandado erigir a estátua de Dioniso. A cultura, outrora privilégio da aristocracia, tornou-se acessível aos homens comuns. O governo de Pisístrato levou Atenas a tornar-se a capital cultural dos gregos" (SILVA, 2009, p. 78)

${ }^{3}$ A palavra hybris remete à desmedida, à ultrapassagem do limite normalmente cometido pelo herói trágico, tanto acarretada pelo estado de espírito agitado pela paixão ou pela força dos afetos (prazer, amor, ódio), quanto a expressão deste estado de espírito marcado pelo seu sofrimento.
} 
sucumbir por sua desmedida. O homem trágico incorre em hybris por seu descomedimento ante as adversidades.

É em contraposição ao homem trágico ligado ao pathos trágico que traremos a discussão o modelo socrático/platônico como contraponto Para tanto, nos utilizaremos dos diálogos platônicos: Laques, Protágoras e Górgias, como textos basilares que servirão de aporte teórico quanto ao problema da possiblidade da akrasia. O homem acrático para Platão seria um homem vicioso, perverso, mau, em suma, aquele que é levado pelas paixões. Quanto ao teatro trágico, nos utilizaremos dos helenistas, Jean-Pierre Vernant e Romilly.

Deste modo, notamos que este estudo se dividirá em duas partes: o momento trágico da filosofia em um primeiro momento e a proposta platônica da possibilidade da akrasia em um segundo momento. Enfatizaremos tantos a disparidades como as aproximações entre esses dois períodos da filosofia grega por acreditamos que existem laços argumentativos e conceituais que os entrelaçam

\section{0 pathos $^{4}$ Trágico $^{5}$ na filosofia clássica}

O fenômeno trágico emerge no contexto da antiguidade clássica, mais precisamente na Grécia do século V a. C. Momento de efervescência cultural onde a chamada democracia ateniense florescia. A tragédia possui íntima ligação com o teatro, que por sua vez era carregado de muitos vetores como a religiosidade, civilidade, educação e política. Ou seja, a representação teatral expressa os elementos históricos e sociais de sua época que passam por uma sensível torção quanto aos valores precedentes. Assim, entendemos que quando pensamos o lugar do elemento trágico na cultura ocidental, lidamos também com uma gama de outros efeitos que estão vinculados intrinsecamente com o modo de ser do homem.

Para o helenista, Jean-Pierre Vernant:

\footnotetext{
${ }^{4}$ Para Loraux o pathos é: o que se sofre, o sofrimento, mas também a experiência que, para os humanos, se adquire somente na dor. Pronunciada, a palavra páthos difere apenas por uma letra de máthos, nome do conhecimento adquirido, e, explorando essa pequena diferença, Ésquilo formou o adágio páthei máthos (Agamêmnon, 177; cf. 249-50), que é a quintessência do trágico. "No sofrimento, o conhecimento", ou ainda: "experiência dá sapiência". É por ter sofrido que se compreende [...]. (Loraux, 1992, p. 27). Notamos, desse modo a íntima relação entre o pathos e o indivíduo guiado pelas paixões.

${ }^{5}$ A tragédia grega configura-se como fruto de um momento histórico, e que, portanto dialoga com incontáveis ramos do fazer do homem desse período. A ideia que este parágrafo busca sublinhar é que se tais fenômenos forem analisados de forma particularizada, a visão que temos desse tempo pode ser distorcida. Não raro os autores que se debruçam sobre esta temática escrevem sobre a política, a religião, a poesia, mas ressaltando a importância de vermos esses conceitos como fazendo parte de um todo.
} 
[...] a tragédia instaura, no sistema das festas públicas da cidade, um novo tipo de espetáculo; além disso, como forma de expressão específica, traduz aspectos da experiência humana até então desapercebidos; marcam uma etapa na formação do homem interior, do homem como sujeito responsável (VERNANT, 2005 p. 1).

Seguindo esse fio notamos que a tragédia expõe certa desarticulação do kosmos e propõe uma nova configuração deste a partir de ações que estão de acordo com novos valores insurgentes e que tiram do eixo os antigos oferecidos pela era homérica. A tragédia é uma poética da ruptura do kosmos $^{6}$.

$\mathrm{Na}$ tragédia ática o adjetivo trágico é usado com o intuito de descrever um destino (moira) fatídico, no qual o homem é impelido a lutar contra forças que desconhece. Comete desequilíbrios que muitas vezes se revertem em ações que o conduzem a seu próprio fim. A tradição, nessa direção, se apresenta como uma contradição, geralmente revelada pela ironia trágica, espécie de efeito narrativo que acentua a ambiguidade contida no ato ilocucionário das personagens envolvidas no combate argumentativo, frequentemente exemplificado nos momentos de conflito entre coro e personagens.

Se puxarmos o fio da tradição grega, notaremos que os elementos que a constituem se revelam como um emaranhado de perspectivas que dialogam proximamente, que por algum motivo não permitem examinar um dado aspecto isoladamente. Dito de outro modo, o espírito ou essência do pensamento clássico caracteriza-se pela interligação de fenômenos que vistos de forma separada podem distorcer seus significados originários. Nesse aspecto, a tragédia só foi possível com o advento da democracia ateniense. No mundo grego, o natural e o sobrenatural se fundem na literatura, na poesia e na religião.

O herói trágico é aquele que após muitos pesares, percebe que caiu na armadilha montada pelo destino. Os tragediógrafos montam ou tecem tais armadilhas através de tropos, golpes do destino, "enganos", em suma, a partir de estratégias que ligam a personagem à pergunta: “o que farei?”. O herói trágico é a hipótese que se confunde com tal perspectiva, como sabemos estas, as perspectivas, são as molas que impulsionam as questões relativas ao trágico, ou à tragicidade. "o grande número de ensaios", sobre o trágico, "explica-se justamente pela ausência de certezas (ROMILLY, 1998, p. 13)”.

\footnotetext{
${ }^{6}$ De um lado a tragédia significa em si mesmo uma ruptura, na sua própria estrutura interna (mas sempre se pautando no mito): a passagem do herói de uma situação normalmente boa para a desgraça, de outro: a tragédia representa duplamente outras rupturas:

I - O rompimento com a ordem (cosmológica) anterior vigente, a mudança dos deuses antigos pelos novos, a passagem dos titãs para os deuses olímpicos.

II - Essa situação espelha as condições históricas da própria Grécia no período: a mudança do ordenamento político e jurídico na cidade, o nascimento da democracia em contraposição a tirania absoluta do regime anterior.
} 
Como vimos anteriormente, o herói trágico caminha à beira de um abismo, aceita a complexidade da sua existência e tenta responder à pergunta “o que fazer?", ante aos infortúnios que lhe são impostos pelo destino (moira). Nas narrativas trágicas os protagonistas passam por uma espécie de educação pela dor. Basta lembrarmo-nos das duas famílias que figuram como maiores representantes de tal gênero narrativo: os átridas ${ }^{7}$ e os labdácias ${ }^{8}$. Exemplos das máculas que mancham e marcam o fenômeno trágico tingindo tais narrativas com a rubra marca da morte como consequência de ações desmedidas que se perpetuam de geração para geração. O conceito de miasma $a^{9}$ traduz tais infortúnios consanguíneos.

Evocamos a tragédia grega para demostrar que o homem pré-socrático encenado nas peças deste gênero era envolvido pela aura que emanava do patrono do teatro trágico, a saber, Dioniso, que por sua vez representava um modo de fruição ligado ao elemento orgiástico traduzido em uma espécie de embriaguez da alma, dos sentidos. O homem trágico é um homem levados pelas paixões. Incontinente quanto às afecções, o homem tinha sua existência legada aos excessos expressos pelas paixões e pelos prazeres. Destarte, a relação entre o elemento dionisíaco contido nas tragédias áticas foi amplamente estudado pelo filósofo alemão Nietzsche (1844-1900) em obras como A Filosofia na Era Trágica dos Gregos, O Nascimento da Tragédia, A Visão Dionisíaca do Mundo. Nietzsche foi um ferrenho crítico do aspecto centralizador da razão nascida com Sócrates. Sobre a crítica ao modelo socrático, Nietzsche nos diz que: "Reconheci Sócrates e Platão como sintomas e declínio, como instrumento da dissolução grega, como pseudogregos, como antigregos” (NIETZSCHE, 2014, p.18).

$\mathrm{Na}$ era trágica, o modelo de homem que nos é apresentado é aquele que sucumbe aos seus desejos, que mergulha em seu abismo interior ao ponto de quase sucumbir aos seus impulsos. O imperativo que o guia está longe da mesura, da harmonia. Notaremos no típico que se segue que este ethos trágico não se configurará quanto à proposta platônica de uma cidade ideal. Tanto os governantes quanto os governados são seres que primam pela medida e pelo

\footnotetext{
7 “A família dos átridas ocupa três tragédias de Ésquilo, dentre as sete que possuímos, uma de Sófocles (Électra), e quatro de Eurípedes (Orestes, Électra, Ifigênia em Áulida, Ifigênia em Táurida)” (SILVA, 1998 p. 138-139).

8 "A família dos labdácias não recebeu menor quinhão, muito pelo contrário. A juventude de Laio, o pai de Édipo, é marcada por assassinatos, aos quais se dedicam as tragédias perdidas como a Antíope de Eurípedes. Quando se tornou rei ele foi ameaçado de ser morto pelo próprio filho; ao nascer esse filho trata de fazê-lo desaparecer, mas inutilmente: em virtude de uma série de enganos preparados pelo destino, Édipo mata o pai, casa-se com sua própria mãe e gera filhos que de certa maneira são seus irmãos". (ROMLLY, 1998, p. 139).

${ }_{9}^{9}$ Míasma, de míaino=tingir, manchar, sujar. Que cumpria apagar por rito purificador (katharmós). Elemento utilizado para de forma metafórica indicar que o erro cometido pelo herói trágico recairia sobre as gerações vindouras, como exemplo maior, temos o caso de Antígona e de seus irmãos que carregam consigo as chagas abertas por seu pai Édipo. Acrescente-se, desse modo, que essa nódoa provém de fora e não da consciência, podendo propagar-se como um contágio. A agonia não cessa com a morte, retumba e vibra nas ações do porvir.
} 
autocontrole. A cidade espelha o corpo social. Cidade e cidadãos são vistos como um organismo só, coeso e virtuoso. Estamos nos referindo à cidade ideal pensada por Platão em sua República.

\section{A possibilidade da akrasia em Platão e o lugar do logos na filosofia}

Ainda no século $\mathrm{V}$ a.C. assistimos ao nascimento de um dos sistemas filosóficos mais célebres do cânon da literatura filosófica. Estamos nos referindo ao platonismo/socratismo. Entendemos este momento da história da filosofia como uma espécie de antípoda ao momento trágico. Se na era trágica as ações humanas se traduziam ao pathos, na era socrática teremos no logos seu elemento fundamental. O homem trágico é o homem guiado por seus instintos, pelas sensações e pela desmedida. É na filosofia socrático/platônica que assistimos emergir o problema da possibilidade da akrasia.

O homem acrático seria o homem que não tem o controle de si, que não controla suas paixões. Para Platão a akrasia se aproxima de certo desequilíbrio das paixões e a perda da autonomia é uma característica da akrasia, por causar também a perda da autonomia. Vale ressaltarmos que a postura socrática difere da platônica quanto a este problema. Sócrates nega a possibilidade da akrasia, tendo em vista que o homem virtuoso jamais recairia em erro. Para este, o homem que recebesse uma educação virtuosa ${ }^{10}$ não incorreria em erro ou desvio exatamente pelo conhecimento de si.

Sobre a akrasia, Feitosa diz que

O termo a-crasia significa o desgoverno da alma, a falta de controle mediante os conflitos causados pelos desejos e paixões que conduzem o homem ao erro. É um tipo de desmedida. O homem que não sucumbe ao erro é aquele que pondera as suas ações. É necessário, portanto, ponderar entre os excessos e a carência das coisas desejadas. (FEITOSA, 2017, p.217).

Notemos que as características apresentadas pela autora quanto ao homem acrático são quase que uma descrição do homem trágico supracitado neste estudo. O homem trágico é dionisíaco enquanto que o homem platônico é apolínio. O homem apolíneo seria aquele levado pela harmonia, pela mediania e virtuosidade; em consequência dessas características desejaria e praticaria o bem. Conhecer o bem não torna uma pessoa boa, mas praticar o bem pode tornála.

A relação agonística entre o deus Apolo e Dioniso é um dos problemas centrais do pensamento nietzschiano, e se apresenta como elemento constitutivo de um fazer artístico que

\footnotetext{
${ }^{10}$ Entendemos que o termo virtude é o mais adequado para nos referirmos ao termo grego areté. Para Zingano areté "é um termo que indica a excelência moral". (ZINGANO, 2008, p.78).
} 
prime pela grande saúde, que se efetivaria pela afirmação regozijante da existência, pelo caráter afirmativo e pelos impulsos que fariam com que a vida deixasse de ser um erro. A influência do devir heraclítico é um fenômeno que se apresenta de forma contundente nos escritos nietzschianos, em contrapartida ao pensamento parmenidiano. Nos primórdios da tragédia grega podemos notar certa conexão com os impulsos mais primitivos do homem, inconscientes e distantes da dialética socrática que, segundo o filósofo, maculara como sua nódoa racionalista a pluralidade dos impulsos mais primitivos. O texto $A$ visão dionisíaca do mundo resgata no berço heleno tais características. A decadência que Nietzsche tanto aponta na cultura ocidental parece ter suas raízes fincadas no surgimento do logos grego e, principalmente, na racionalidade dialética provinda deste, via socratismo/platonismo.

Sócrates atua como uma espécie de médico que se utiliza do logos como procedimento de cura (pharmakon) em seu método (maiêutica). O homem bom e belo seria, na perspectiva socrática, essencialmente virtuoso e, exatamente por isso, não cometeria desmedidas. Vale ressaltar que a filosofia socrático/platônica tem em seu cerne a formação ética e política dos cidadãos. A filosofia tradicionalmente busca tratar de problemas eternos e perenes, dai a filosofia antiga ser denominada de essencialista. Nota-se que nos diálogos de maturidade Sócrates buscar pensar a que estão da unidade das coisas, ou seja, o que é X? O elenkhos ${ }^{11}$ é o procedimento investigativo que marca essa fase.

Os diálogos de juventude de Platão têm Sócrates como personagem central. A postura socrática surge em primeiro plano nessa fase. Como visto anteriormente, o homem trágico tinha como fundamental idiossincrasia o fato de ser levado pelos sentidos, pela exacerbação estética que o teatro proporcionava. Suas ações estavam ligadas ao destino e as sensações. É como uma espécie de antípoda ao período trágico que surge a proposta socrático/platônica. Nesta o homem deveria desvencilhar-se de tudo o que aguilhoava e oprimia sua autonomia. Com sabemos a postura socrática difere da postura platônica quanto ao problema da akrasia. Para Sócrates a ação acrática não é intencional, o homem peca por desconhecimento ${ }^{12}$. Já para Platão tal ação pode se dar de forma deliberada.

Como pano de fundo das disputas entre Sócrates e seus opositores, os sofistas, temos a distinção entre essência e aparência. Os argumentos sofísticos se apresentam carregados de

\footnotetext{
11 Denomina-se elenchos o processo dialético pelo qual o diálogo prossegue de hipótese em hipótese até ao impasse.

12 Postura denominada de intelectualista. Nesta o homem seria bom por ter sido educado assim e não seria capaz de recair em desmedidas exatamente por ter conhecimento ou consciência de suas ações. Sobre essa questão FEITOSA nos informa que "Sócrates e visto como intelectualista ao justificar que aquele que conhece o bem não quer o mal; o mal, na verdade, é produto da ignorância do bem” (FEITOSA, 2006, p. 34)
} 
fragilidade frente à dialética socrática, que, por sua vez apresenta um método mais rígido na busca pela verdade. Na filosofia tradicional entendemos verdade como unidade. Ademais, argumentos sofísticos ${ }^{13}$ são amplamente atacados por Platão, via seu personagem conceitual Sócrates.

É tendo em vista o problema da akrasia que evocaremos alguns dos diálogos mais célebres da produção platônica. No diálogo platônico Laques, somos apresentados ao problema da akrasia e sua relação com as virtudes. No referido diálogo surge à questão se a virtude é una ou se existem várias virtudes. Esse problema se relaciona à akrasia porque o homem virtuoso seria aquele que tem autodomínio.

A maiêutica se apresenta como um dos conceitos fundamentais da filosofia platônica, exatamente por apontar como se processa seu pensamento. Sócrates nos relata que sua mãe era parteira e que tinha como função trazer à luz pessoas e que seu ofício filosófico se aparenta com o de sua mãe com a diferença que trazia a luz ideias, partejando almas e não corpos. A maiêutica, como se percebe, apresenta íntima ligação com a própria ideia de conhecimento, pois difere o verdadeiro do falso, destacando por notar quais frutos vingaram. Como exemplo, Sócrates põe Teeteto a refletir sobre o que é conhecimento e trabalha de modo a fazê-lo metabolizar, digamos assim uma definição, como anteriormente exposto. Portanto, a maiêutica é compreendida como ferramenta que instiga o pensamento a deliberar sobre os fenômenos que se apresentam ao entendimento.

No Laques vemos surgir o problema da coragem como virtude. Temos nesse diálogo a maiêutica sendo usada como procedimento investigativo. Consideramos Laques como uma obra de exortação e de convite à prática do exercício da verdade, como bem aponta o termo em destaque. Posto que temos a relação entre o logos e a vida (bios) na cidade (polis), sendo, desse modo, interessante para a coesão entre os indivíduos da polis grega pensar nos dispositivos fundamentais para a boa relação destes. E a questão pedagógica proposta pelos ethos socrático via o diálogo Laques nos parece basilar quanto à discursão sobre a virtude. Em suma, tal problemática nos faz refletir sobre a vida civil ateniense. É para um Platão político que estamos apontando e de um Sócrates preocupado com questões pedagógicas.

\footnotetext{
${ }^{13}$ Os Sofistas são geralmente apontados como comerciantes de ideias que não se preocupam com o saber seguro e que por vezes relativizam o conhecimento a ponto de deformá-lo a seu modo.
} 
Outro diálogo também fundamental para o problema da akrasia é o Protágoras ${ }^{14}$. Gostaríamos de apontar nesse diálogo dois pontos que consideramos fundamentais. O primeiro seria dar continuidade à questão dualidade ou pluralidade das virtudes posto no Laques. E em segundo a relação entre o homem virtuoso e o acrático. Quanto ao primeiro problema, Sócrates acossa Protágoras do seguinte modo: "Explica-me isso agora com mais particularidades, e se a virtude é, de fato, algo completo, vindo a ser parte dela a justiça, a temperança e a santidade, ou se todas essas qualidades, como disse há pouco, são apenas nomes diferentes de uma única unidade". (329d) notamos, desse modo que o problema da fragmentação ou não das virtudes ainda é central para Platão. Já quanto à causa da akrasia, neste mesmo diálogo, Sócrates, dirigindo-se a Protágoras nos informa que: "E todas as pessoas a quem eu perguntei qual era a causa de semelhante fato, responderam que a causa de fazerem o que fazem é ficarem dominados pelos prazeres, ou pela dor, ou por qualquer das paixões a que a pouco me referi”" (352e). O conhecimento das virtudes leva o homem à sabedoria. Segundo Claude Mossé: "Sócrates se nos apresenta como um espírito vigoroso, irônico e persuasivo ao mesmo tempo, preocupado com a felicidade do homem e convencido de que essa felicidade só pode advir da eterna busca de justiça, no homem e na cidade”. (MOSSÉ, 1997, p. 83.)

Apenas o conhecimento sobre si mesmo guiaria o homem contra os excessos e o afastaria da desmedida. O problema da virtude é a questão central pensada por Platão no referido diálogo porque apenas o homem virtuoso age moralmente. Enquanto a isto Sócrates nos diz que "Meu único objetivo, lhe disse, ao apresentar-te todas essas perguntas, não é outro senão o de examinar os problemas relativos à virtude e o que venha a ser a virtude em si mesma”. (361a). Os Sofistas são geralmente apontados como comerciantes de ideias que não se preocupam com o saber seguro e que por vezes relativizam o conhecimento a ponto de deformá-lo a seu modo. Como antídoto a essa postura temos a postura socrática que visa à busca pela verdade e pela realidade se utilizando de métodos distintos dos utilizados pelos sofistas.

\section{CONSIDERAÇÕES FINAIS}

Buscamos neste estudo demostrar as disparidades e aproximações existentes entre o período trágico e o período ligado ao logos na história da filosofia grega. Ambos esses períodos se inscrevem na chamada era clássica ou antiga da cultura helênica e fazem parte de uma

\footnotetext{
${ }^{14}$ No próprio diálogo Protágoras, Sócrates nos oferece sua definição de sofista ao relatar para Hipócrates que "O sofista, Hipócrates, não será por ventura, uma espécie de mercador, ou traficante de vitualhas para alimentar a alma? A mim, pelo menos, é o que eles parecem ser." (313 c).
} 
controversa discussão quanto temos em mira o nascimento da própria filosofia. Podíamos nos deter na querela que divide especialistas quando a continuidade e a descontinuidade apresentada na discussão que tem como pano de fundo a distinção entre mithos e logos, contudo consideramos a alternativa de discutir tais disparidades dando ênfase na relação entre pathos e akrasia.

A referida pesquisa dividiu-se em dois momentos. Primeiramente detemos nossa atenção no período trágico buscando demostrar o tipo de homem que a educação trágica apresentava. Como sabemos esse é o momento da chamada democracia ateniense. O homem trágico tem como marca fundamental o mergulho no delírio dionisíaco, patrono do teatro grego. Essa potência geralmente é relacionada com o lado mais sóbrio do homem.

Já em um segundo momento, perscrutamos o problema da possibilidade da akrasia nos diálogos platônicos de juventude. O problema da akrasia em Platão mostra-se célebre e desperta o interesse dos mais variados especialistas. Acreditamos que exista um movimento agonístico entre esses dois períodos da Filosofia Antiga, o homem acrata apresentado por Platão, por vezes parece uma descrição do homem trágico. Isso se dá, segundo nosso ponto de vista, porque o homem trágico é guiado pelas emoções, enquanto que o homem virtuoso problematizado por Platão tem como norteador o logos. Tanto Górgias como Protágoras são eminentes sofistas e seu método passa pelo convencimento via doxa, de uma epistemê, ou saber seguro. O convencimento através da oratória é a marca mais fundamental da sofística, e pode, por não raras vezes, conduzir ao relativismo epistêmico, ou aparente. Contudo se todos tem a justa medida então à justa medida carece de justeza para todos. $\mathrm{O}$ conflito se dá a partir dos pares: essência/aparência; verdade/falsidade. A proposta filosófica platônica funciona como uma espécie de elemento catalizador do pensamento antigo e por extensão vetor de uma tradição dualista e essencialista que marcou a invenção de um modo de pensar que deixou marcas indeléveis para a posteridade.

\section{REFERÊNCIAS BIBLIOGRÁFICAS}

FEITOSA, Zoraida Maria Lopes. A Questão da Acrasia na Filosofia de Platão. Revista Prometeus Filosofia. Alagoas, ano 10, nº 23 - maio/agosto de 2017.

FEITOSA, Zoraida Maria Lopes. A questão da unidade e do ensino das virtudes em Platão. São Paulo, 2006. 


\section{A PONA

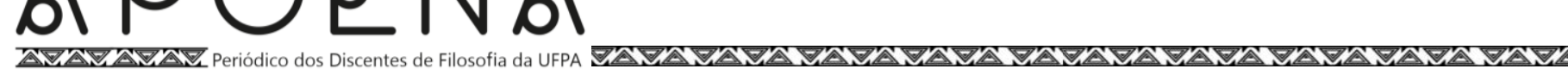

LORAUX, N. (1992). A tragédia grega e o humano. In A. Novaes (Org.). Ética. São Paulo: Companhia das Letras.

MOSSÉ, Claude. Atenas, a história de uma democracia. Brasília: UNB, 1997.

NIETZSCHE, Friedrich. Crepúsculo dos ídolos ou como se filosofa com o martelo. Petrópolis, RJ: Vozes, 2014.

PLATÃO. Diálogos. Volumes I e II. Tradução: Carlos Alberto Nunes. Belém: EDUFPA, 1980.

PLATÃO. Diálogos. Volumes III e IV. Tradução: Carlos Alberto Nunes. Belém: EDUFPA, 1980.

ROMILLY, Jacqueline. A Tragédia Grega. Brasília-Editora Universidade de Brasília, 1998.

SILVA, FRANCISCO DA CUNHA. O Trágico como Condição do Humano: Ressignificação da tragédia na história da civilização ocidental. Tese (Doutorado em Ciências Humanas), Centro de Filosofia e Ciências Humanas, Universidade Federal de Santa Catarina. Florianópolis, 2009.

VERNANT, Jean Pierre. Mito e Tragédia na Grécia Antiga/Jean-Pierre Vernant e Jean-Pierre Vidal-Naquet. São Paulo: Perspectiva, 2005.

ZINGANO, Marco. Estudos de Ética Antiga. São Paulo: Discurso Editorial, 2009. 